\section{0 francês com objetivos universitários na formação de futuros professores da Universidade Federal do Ceará}

Ticiana Telles MELO (UFC) ticianatellesmelo@gmail.com

Recebido em: 28 de maio de 2018. Aceito em: 12 de set. de 2018.
MELO, Ticiana Telles. O francês com objetivos universitários na formação de futuros professores da Universidade Federal do Ceará. Entrepalavras, Fortaleza, v. 8, n. 3, p. 352-363, outdez/2018

Resumo: A internacionalização das instituições de ensino superior no Brasil é uma realidade inegável e inquestionável e tem trazido várias mudanças para o seio da comunidade acadêmica. No bojo dessa inovação, encontra-se a percepção de que as línguas estrangeiras ocupam um lugar importante, como um dos "passaportes" para o sucesso da internacionalização. Este artigo pretende apresentar o ensino de língua francesa para fins acadêmicos, mais conhecido como francês com objetivos universitários, situando-o no panorama do ensino de línguas sob a abordagem voltada para a ação. A metodologia utilizada para a pesquisa é bibliográfica, dentro das áreas de ensino de línguas, de estágio e formação docente, complementada pela pesquisa feita no chão da sala de aula, nas disciplinas de estágio docente do curso de Letras Português-Francês da Universidade Federal do Ceará.

Palavras-chave: Estágio curricular. Francês com objetivos universitários. Ensino de línguas estrangeiras. 
Abstract: The internationalization of higher education institutions in Brazil is an undeniable and unquestionable reality and has brought several changes within the academic community. In the heart of this innovation there is the perception that foreign languages occupy an important place, as one of the "passports" for the success of internationalization. In this work, we intend to present the teaching of the French language for academic purposes, better known as French with university objectives, placing it in the landscape of language teaching under the action-oriented approach. We have a bibliographic methodology in the areas of language teaching, internship and teacher training that is complemented by the research done on the floor of the classroom, in the disciplines of teaching stage at Federal University of Ceará.

Keywords: Internship. French with university objectives. Teaching foreign language.

\section{Introdução}

Com este artigo, pretendemos discutir os processos formativos vivenciados no curso de Letras Português-Francês da Universidade Federal do Ceará (UFC) no espaço temporal delimitado pela implantação do Programa Francês sem Fronteiras nesta instituição, ou seja, desde o ano de 2013 até os dias de hoje.

Para tanto, trabalharemos brevemente a questão da internacionalização das universidades brasileiras e a consequente valorização das línguas estrangeiras neste panorama, para chegarmos ao cerne da inquietação desta escrita: a proposta de ensino para o francês que acompanha esse momento, chamada de francês com objetivos universitários (FOU) e seus impactos na formação do futuro professor de francês língua estrangeira (FLE).

\section{O fenômeno da internacionalização dos estudos e seu impacto nas línguas estrangeiras}

A internacionalização tem sido uma questão cada vez mais frequente nas diretrizes das instituições de ensino superior. Participar de redes internacionais, responder a apelos multilaterais, inserir-se em um ambiente de ensino, pesquisa e produção sem fronteiras são condições de excelência que contribuem para uma boa avaliação das universidades, segundo os critérios vigentes de ranqueamento. Santos e Almeida Filho (2012, p. 50) analisam as transformações das e nas universidades ao longo do tempo:

A Universidade deve sua reconhecida longevidade à capacidade que tem mantido para se transformar e adaptar à evolução do mundo. Por vezes, por iniciativa própria, outras vezes, em resposta a estímulos exteriores de caracter mais ou menos impositivo, sempre ou quase sempre em equilíbrio tenso 
V. 8 (3)

$352-363$

out-dez

2018 entre reflexão autônoma e ressignificação à heteronomia, entre impulsos pró-ativos e reativos, a verdade é que as Universidades de hoje inscreveram a mudança no seu código genético porque, na seleção natural, se secundarizam as que não souberam fazê-lo.

O Programa Francês sem Fronteiras não pode ser entendido sem uma investigação sobre o processo de internacionalização pelo qual as mais diversas instituições de ensino brasileiras têm passado, uma vez que ele é reflexo e resposta à iniciativa mais representativa de mobilidade internacional: o Programa Ciência sem Fronteiras (ABREU E LIMA, 2016).

Lançado pelo governo federal em 2011, o Ciência sem Fronteiras (CsF) visa, conforme apresentação disponível no site ${ }^{1}$ do programa: "promover a consolidação, a expansão e internacionalização da ciência e tecnologia, da inovação e da competitividade brasileira, por meio de intercâmbio e da mobilidade internacional".

Logo nos primeiros editais do CsF, constatou-se a deficiência do estudante universitário no que diz respeito ao conhecimento de línguas estrangeiras. Para suprir essa carência, o Ministério da Educação criou o Inglês sem Fronteiras que, em 2014, transformou-se em Idiomas sem Fronteiras (IsF), cujo objetivo, conforme publicado no site do programa, é a promoção de "uma política linguística para a internacionalização do Ensino Superior Brasileiro, valorizando a formação especializada de professores de línguas estrangeiras".

A fim de compreender a globalização, alguns teóricos preferem entendê-la em sua multiplicidade, utilizando o vocábulo no plural (globalizações), acontecendo o mesmo com a "mobilidade". Assim, é preferível falarmos em "mobilidades", haja vista a vastidão e a diversidade das referências que essa palavra evoca.

Entre as práticas que caracterizam a internacionalização acadêmica, a mais conhecida é a mobilidade, que se apresenta em duas versões: a mobilidade de entrada, em que a instituição organizase junto com seu alunado para a recepção de alunos estrangeiros; e a mobilidade de saída, na qual a universidade se prepara e orienta seu aluno para uma experiência de estudos no exterior. Nesse processo, procura-se também que a internacionalização atinja as três esferas de

\footnotetext{
1 Disponível em: <http://www.cienciasemfronteiras.gov.br/web/csf/o-programa>. Acesso em: 25 mar. 2018.

${ }^{2}$ Disponível em: <http://isf.mec.gov.br/programa-isf/entenda-o-isf>. Acesso em: 25 mar. 2018.
} 
atuação da instituição, a saber: ensino, pesquisa e extensão. Além disso, incentiva-se a mobilidade que se dá em casa, por meio, por exemplo, de cursos e programas em línguas estrangeiras, entre outras políticas institucionais.

É nesse contexto múltiplo que o francês com objetivos universitários (FOU) encontra seu espaço. Para responder a uma exigência de uma formação linguística mais específica, aquela de alguém interessado em fazer seus estudos superiores (ou parte deles) em países francófonos, o FOU, sob o ângulo do aprendiz, caracteriza-se por ter:

objetivos mais precisos, centrados na vivência e nos bons resultados universitários;

formação que se dá em um curto período, ainda no país de origem;

concentração de temas e competências voltados ao mundo dos estudos.

Do professor, exige-se a imersão em domínios de conhecimentos que não são necessariamente aqueles de sua formação inicial e, por isso, para desenvolver seu trabalho, ele deve coletar dados e entrar em contato com atores do meio socioprofissional em questão. Por fim, na maioria dos casos, o professor de cursos FOU é também o elaborador do material didático a ser utilizado.

Um programa de preparação para a mobilidade (FOU) supõe para o professor-elaborador etapas institucionais e didáticas muito diferentes daquelas que supõe um curso de Francês Generalista (FG). A relação estreita com necessidades externas conduz o professor a coletar dados adaptados e a didatizar suportes específicos às situações de mobilidade. ${ }^{3}$ (ALBUQUERQUECOSTA; PARPETE, 2016, p. 49-50, tradução nossa).

Éimportante colocar o FOU eo FLE - oúltimo aqui compreendido como o francês generalista (FG) por apresentar objetivos amplos, com uma formação a longo termo e propondo diversidade de temas e competências -, como síncronos, colaborativos e não excludentes. São, assim, abordagens que convivem e que podem contribuir para a formação dos estudantes, de acordo com a finalidade do projeto de aprendizagem que ele apresentar.

O FLE, enquanto disciplina, é um campo relativamente jovem

\footnotetext{
3 Texto original: "Un programme de prépararion à la mobilité (FOU) suppose pour l'enseignant-concepteur des démarches institutionnelles et didactiques três différentes de ce que suppose um cours de Français Général (FG), La relation três étroite à des besoins externes condiuit l'enseignant à collecter des données adaptées et à didactiser des supports spédifiques aux situations de mobilité."
} 
V. 8 (3)

$352-363$

out-dez

2018

(CUQ; GRUCA, 2005) e os autores que se debruçam sobre a evolução das diversas metodologias e abordagens de ensino-aprendizagem de francês - tais como Cuq e Gruca (2005), Barthelemy (2007), entre outros - são unânimes em dizer que vivemos sob a égide da abordagem de ensino orientada para a ação que, por sua vez, bebe na fonte do documento escrito pelo Conselho da Europa (2001) ${ }^{4}$ no início deste século, e cujos simbolismos não são desprezíveis, orientados pelo "Quadro Europeu Comum de Referência para as Línguas" (QECR) ${ }^{5}$.

Tanto o FLE quanto o FOU se baseiam no princípio do ensino orientado para a ação. Em ambos os casos, as tarefas são o objetivo final das unidades didáticas. O QECR enfatiza a importância da execução das tarefas, sobretudo nos capítulos 2, 4 e 7, além de considerar os aprendizes como atores sociais que:

[...] desenvolvem um conjunto de competências gerais e, particularmente, competências comunicativas em língua. As pessoas utilizam as competências à sua disposição em vários contextos, em diferentes condições, sujeitas a diversas limitações, com o fim de realizarem actividades linguísticas que implicam processos linguísticos para produzirem e/ ou receberem textos relacionados com temas pertencentes a domínios específicos. Para tal, activam as estratégias que lhes parecem mais apropriadas para o desempenho das tarefas a realizar. O controlo destas acções pelos interlocutores conduz ao reforço ou à modificação das suas competências. (CONSELHO DA EUROPA, 2001, p. 29).

Entendemos que o objetivo final da aprendizagem sob a abordagem baseada na ação não é apenas a comunicação, mas o desempenho de atividades interativas que utilizem a língua estrangeira. No caso do FOU, podemos exemplificar que as tarefas finais devem ser direcionadas para o mundo da compreensão da mobilidade, assim, são solicitadas atividades que abordam a compreensão escrita de documentos universitários (como matrizes curriculares e curricula vitae) e a produção escrita de uma carta de motivação para estudar no exterior. Na oralidade, espera-se, por exemplo, a compreensão de uma explicação teórica do assunto de formação do estudante e a capacidade de expressão no mesmo domínio.

4 O Conselho da Europa é uma organização intergovernamental com sede em Estrasburgo (França) que tem como primeiro objetivo promover e garantir a dignidade dos cidadãos através do respeito pelos valores fundamentais como a democracia e os direitos humanos. Disponível em: <https://www.coe.int/pt/web/about-us/do-notget-confused>. Acesso em: 6 out. 2017.

5 Disponível em: <http://area.dge.mec.pt/gramatica/Quadro_Europeu_total.pdf>. Acesso em: 6 out. 2017. 
Enquanto formadores de futuros professores de francês, encontramo-nos frente a uma nova realidade formativa que agrega mais uma vertente: a preparação para o ensino para a mobilidade. Em momentos anteriores a este, no lidar do campo do estágio, já houve a inclusão do francês instrumental, também conhecido como francês para fins de leitura, hoje revisitado em algumas universidades como francês com fins acadêmicos. Mais recentemente, incorporou-se a este campo a didatização das tecnologias da informação e da comunicação (TICs). O que é preciso, a nosso ver, é acolher cada uma das novidades que, sem dúvida, são frutos de pesquisas e têm seus méritos indiscutíveis. Cabe ao professor do estágio integrar as diversas perspectivas, no sentido de enriquecer, multiplicando as possibilidades de chão de aula para o formando.

Um grande desafio do qual não podemos esquecer é que, diferentemente das outras formações que o estágio propõe - a saber, a formação em FLE, em francês sobre objetivos específicos (FOS), com ênfase em TICs, para as quais o aluno já teve um contato, mesmo que apenas quando ele mesmo aprendia francês (ou uma outra língua estrangeira) -, o FOU, por formar alunos em mobilidade (que em absoluto não é o perfil do curso de licenciatura em Letras PortuguêsFrancês), é inteiramente novo para nosso alunado. A integração entre o que o aprendiz já conhece e aquilo que ele aprende - tão cara a Tardif (1992) - é uma passagem difícil.

\section{Formando professores de francês para a mobilidade}

Para entender o estágio, convocamos Almeida e Pimenta (2015, p. 30), para quem o estágio configura-se como um "espaço/tempo favorecedor da compreensão a respeito da profissionalidade docente" e por isso trazemos para a formação os diversos campos de conhecimento e produção de conhecimento em FLE. Gautherot (1992, p. 52, tradução nossa) completa essa filiação etimológica entre estágio e o tempo do "estar sendo":

Tempo da pausa e da permanência no escoamento inelutável do tempo cronológico. [...] Tempo do conhecimento, tempo da crítica, tempo da observação, tempo de voltar-se a si mesmo, tempo da desconstrução e da reconstrução, tempo da invenção. ${ }^{6}$

\footnotetext{
${ }^{6}$ Texto original: "Temps de la pause et de la permanence dans l'écoulement inéluctable du temps chronologique. [...] Temps de la connaissance, temps de la critique, temps de l'observation, temps du retour sur soi, temps de la déconstruction et de la reconstruction, temps de l'invention."
} 
V. 8 (3)

$352-363$

out-dez

2018

O curso de Letras Português-Francês da UFC tem em sua matriz curricular duas disciplinas de estágio obrigatórias, diretamente ligadas ao ensino-aprendizagem da língua estrangeira, que são ofertadas nos últimos semestres da licenciatura. Com base na compreensão de marco formativo, somamos um outro componente, chamado Elaboração de Materiais Didático-Pedagógicos em Francês como Língua Estrangeira. Todas as disciplinas são de responsabilidade do Departamento de Letras Estrangeiras. Reforçamos, ainda, que as demais disciplinas do currículo são colaboradoras na formação do professor. Nenhuma delas deve ser meramente centrada em seu conteúdo, mas têm o papel de contribuir para a preparação pedagógica de futuros profissionais críticos e reflexivos.

No atual momento, em nosso curso de Letras, a apropriação do francês sobre objetivos universitários tem se restringido às disciplinas de Estágio 1 e Elaboração de Materiais Didático-Pedagógicos em Francês como Língua Estrangeira. O formato do Estágio 2 ainda segue o padrão de ministração de aulas em FLE, de âmbito generalista. Isto se dá por diversas razões que ultrapassariam nossa discussão neste artigo, mas podemos dizer que os cursos ofertados pelo IsF pelo Núcleo de Línguas (Nucli) em nossa universidade, como em todas as universidades brasileiras, são assegurados por professores bolsistas, selecionados por meio de editais e/ou leitores franceses, engajados no movimento de internacionalização.

É importante acrescentar que os professores do Núcleo de Línguas também estão em formação. Em seu contrato, há um volume de horário destinado aos estudos teórico-práticos da metodologia FOU, sob a orientação do professor referente. Desde o início dessa proposta, temos feito deste momento de estudo uma oportunidade de partilha, em que participam não apenas os bolsistas, mas estudantes voluntários de diversos semestres. Vemos, assim, uma possibilidade nascente de validar as experiências dos bolsistas do Francês sem Fronteiras do Nucli como atividades de estágio de regência, quebrando a rigidez da matriz curricular de nosso curso que, infelizmente, aponta os estágios apenas nos últimos momentos de formação do alunado, contrariando a visão de que a formação pedagógica prática deve ser encarada como um processo contínuo.

Os ventos que pretendem derrubar as estruturas rígidas curriculares nas quais se encontram os estágios acadêmicos já sopram há algum tempo em nossa casa, de maneira tímida, porém, 
ininterruptamente. Os estudantes procuram cada vez mais precocemente a experiência do chão da sala de aula. Assinalamos, assim, a oferta de outras estratégias, como a seleção de bolsistas para atuarem como professores de cursos de Francês para a Comunidade, promovidos pela universidade, com sua oferta de cursos de extensão (campo por excelência da ministração do estágio de regência em FLE). Vários de nossos estudantes têm antecipado a experiência de regência de sala de aula ao serem aprovados no exame de seleção para essas bolsas, que são valorosamente acompanhadas pelo professor referente do curso de Francês para a Comunidade.

Ainda sobre o currículo, vinculamo-nos a Silva (2002) e apontamos que o currículo é um documento de identidade, no qual se inscrevem os percursos (deliberados ou não), as escolhas e as vivências que fazem do sujeito aprendiz quem ele é. Mais ainda: o currículo formal é resultado de uma escolha e nele estão agregados conteúdos julgados pertinentes. No momento em que nos encontramos, o percurso convencional de ensino-aprendizagem do FLE generalista não deve ser mais exclusivista, uma vez que os saberes ligados ao fenômeno da internacionalização dos estudos e seus reflexos na aquisição de línguas estrangeiras têm se constituído como um campo epistemológico e ingressado nas matrizes curriculares de diversos cursos de Letras.

Vejamos, a seguir, as propostas formativas em direção ao FOU e às disciplinas de estágio curricular e outras formas de antecipação da experimentação da prática didática do futuro professor de francês no nosso curso de Letras.

O primeiro estágio tem o formato de disciplina e chama-se Estágio 1: Fundamentos Teóricos para o Ensino de Língua Francesa. Com duração de 64 horas, ele tem uma característica híbrida. Uma parcela das horas-aula é atribuída à aquisição do embasamento teórico, indispensável à experiência que virá em breve, no semestre subsequente, sob a orientação do professor orientador e que anunciará as demais inserções profissionais do futuro professor no chão da sala de aula. Outra parte da disciplina se destina a um estágio de observação que o aluno deve fazer no primeiro semestre do curso de Francês para a Comunidade e nas ofertas dos cursos de Francês sem Fronteiras, vinculados ao Nucli.

Os textos teóricos que compõem a primeira parte da disciplina aportam o conhecimento sobre o ensino de línguas estrangeiras a partir de diversos ângulos. Tratamos questões da política linguística e sua relação com os diversos momentos sócio-históricos das comunidades 
V. 8 (3)

$352-363$

out-dez

2018

concernidas; discutimos aspectos relativos ao campo das línguas estrangeiras e o papel da língua francesa nesse orbital de forças; apresentamos um panorama cronológico (e o mais coerente possível) das diversas metodologias de ensino de línguas estrangeiras, até chegarmos à abordagem baseada na ação, a qual se filia a maioria dos manuais utilizados atualmente nos cursos de FLE. Já vimos, também, que a metodologia FOU vale-se de princípios semelhantes, centrados na ação e na interação graças ao uso da linguagem. Assim, com essa noção da abordagem baseada na ação, entram em cena os textos a respeito da internacionalização e do FOU.

A partir daí, observação e leitura tornam-se um só momento de aprendizagem. Graças ao laboratório que nos é ofertado pelos professores que acolhem os estagiários, os alunos da graduação conhecem realmente, porque dessa vez o fazem sob a ótica do professor, e avant la lettre, a realidade material na qual eles vão atuar no estágio acadêmico supervisionado. Lima (2004, p. 24) explicita o valor do estagiário:

O aluno estagiário, agindo sobre o meio e recebendo a influência deste. Pode, assim, elaborar o seu conhecimento, trabalhando com conteúdos concretos, indissociáveis da realidade social através da reflexão, troca de experiências e interferir de alguma forma, nesta mesma realidade.

Como dissemos, o momento de observação é parte integrante e obrigatória dessa primeira disciplina. Para tanto, ao acompanharem as aulas, os alunos seguem um roteiro de observação previamente discutido em sala, que servirá de base para a composição do relatório de estágio, produção acadêmica exigida para a aprovação da componente curricular. O estudante é igualmente orientado a conversar com o professor responsável pela turma, caso precise sanar alguma dúvida ou tenha questões sobre as atividades propostas.

Em relação a essa etapa, as discussões em sala de aula, a leitura e a avaliação dos relatórios nos têm mostrado alguns resultados importantes e positivos. O interesse e motivação em conhecer e trabalhar com o FOU é uma constante entre os formandos. Contrariamente ao FLE (se este for ensinado a partir de manuais completos, publicados por editoras especializadas), o FOU exige uma postura interativa e atitudes de bricolagem da parte do professor, no que diz respeito aos suportes pedagógicos a serem utilizados em sala de aula (BOUCHET et al., 2016). Essa solicitação é, na maioria das vezes, instigadora e desafiadora, portanto, própria ao caráter intrínseco da atividade do estágio. 
A disciplina Elaboração de Materiais Didático-Pedagógicos em Francês como Língua Estrangeira tem 32 horas-aula e sua ementa aborda avaliação, planejamento, elaboração e aplicação de materiais pedagógicos voltados para a adequação às necessidades e aos interesses dos aprendizes de francês como língua estrangeira. O estudante é, então, levado a produzir materiais coerentes com a proposta metodológica da atualidade. Discutimos a concepção de unidade de ensinoaprendizagem em contextos que valorizem a ação e a interação por meio da comunicação e permitam a integração das atividades centradas no projeto e na autonomia do aprendiz. As ferramentas que permitirão o bom desenvolvimento dessa disciplina são igualmente válidas para o FLE generalista e para o FOU. Apropriar-se desses instrumentos, valendo-se de suas experiências prévias de usuários da língua francesa, de ator social em sala de aula e de professor em formação, é o objetivo final da prática deste componente curricular.

Aproximamo-nos da conclusão do texto, mas gostaríamos de evocar a experiência formativa e coletiva que tem se mostrado ser um grupo de estudos sobre FOU, por nós coordenado. Formado por professor, professor assistente leitor, bolsistas e alunos voluntários de diversos semestres da licenciatura, o grupo tem o objetivo de fomentar a discussão não apenas sobre teorias acerca do FOU, mas sobre o caráter dos estágios no curso de Letras, suas particularidades, exigências e desafios. Acreditamos que a vivência partilhada é uma ocasião de trocas indispensáveis à formação do espírito crítico e criativo do professor em formação.

\section{Conclusão}

Por ser um ritual de passagem, assistido pelos professores referentes e pelos demais formandos, os estágios curriculares mostramse um momento de grande carga simbólica. A somatória entre o disciplinar e o não disciplinar, o obrigatório e o não obrigatório das propostas oxigena o currículo, entendido como escolha e caminho que se faz ao caminhar. A voz de Freire et al. (1991, p. 58) ressoa sempre atual e fundamental:

Ninguém começa a ser educador numa certa terça-feira às quatro da tarde. Ninguém nasce educador ou marcado para ser educador. A gente se faz educador, a gente se forma, como educador, permanentemente, na prática e na reflexão sobre a prática. 
v. $8(3)$

$352-363$

out-dez

2018

$\mathrm{O}$ que aqui mostramos - a abordagem para o ensino representada pelo francês com objetivos universitários - tem servido como lente para a interpretação de um novo campo de trabalho docente e de pesquisa para o aluno formando, além de promover uma prática criativa no que diz respeito à confecção de materiais didáticos.

Por fim, podemos crer que o estágio curricular no curso de Letras Português-Francês da UFC ganha volume com experiências como o FOU, bem como com outras igualmente presentes na matriz curricular que tem como objetivo diversificar o panorama formativo a ser oferecido a seu alunado.

\section{Referências}

ABREU E LIMA, D. M. O programa Inglês sem Fronteiras e a política de incentivo a internacionalização do Ensino Superior brasileiro. In: SARMENTO, S.; ABREU E LIMA, D. M.; MORAES FILHO, W. B. (Org.). Do Inglês sem Fronteiras ao Idiomas sem Fronteiras: a construção de uma politica linguística para a internacionalização. Belo Horizonte: Editora UFMG, 2016.

ALBUQUERQUE-COSTA, H.; PARPETE, C. Introduction à la problématique du Français sur Objectif Universitaire: le cas de l'Université de São Paulo. In: (Orgs.). Français sur Objectif Universitaire: méthodologie, formation des enseignants et conception de programmes. São Paulo: Paulistana, 2016.

ALMEIDA, M. I.; PIMENTA, S. G. Centralidade do estágio em curso de Didática nas licenciaturas: rupturas e ressignificações. In:

Estágios supervisionados na formação docente: educação básica e educação de jovens e adultos. São Paulo: Cortez, 2015.

BARTHELEMY, F. Professeur de FLE: historique, enjeux et perspectives. Paris: Hachette, 2007.

BOUCHET, K. et al. Impact du type de mobilité étudiante sur les programmations en Français sur Objectifs Universitaires. In: ALBUQUERQUE-COSTA, H.; PARPETTE, C. (Orgs.). Français sur Objectif Universitaire: méthodologie, formation des enseignants et conception de programmes. São Paulo: Paulistana, 2016.

CONSELHO DA EUROPA. Quadro Europeu Comum de Referência para as Línguas: aprendizagem, ensino, avaliação. Porto: ASA, 2001.

CUQ, J.-P.; GRUCA, I. Cours de didactique du français langue étrangère et seconde. Grenoble: PUG, 2005.

FREIRE, P. et al. A educação na cidade. São Paulo: Cortez, 1991.

GAUTHEROT, J.-M. Du bon et du mauvais usage des stages. Le Français dans le Monde: recherches et applications, Paris, n. spécial, 1992.

LIMA, M. S. L. O estágio supervisionado como estratégia de integração entre a 
universidade e a comunidade: uma reflexão sobre a experiência de minicurso. In: . A hora da prática: reflexões sobre o estágio supervisionado e a ação docente. Fortaleza: Demócrito Rocha/UECE, 2004.

SANTOS, F. S.; ALMEIDA FILHO, N. A quarta missão da universidade: internacionalização universitária na sociedade do conhecimento. Brasília: Editora Universidade de Brasília; Coimbra: Imprensa da Universidade de Coimbra, 2012.

SILVA, T. T. Documentos de identidade: uma introdução às teorias do currículo. Belo Horizonte: Autêntica, 2002.

TARDIF, J. Pour un enseignement stratégique: l'apport de la psychologie cognitive. Montréal: Les Éditions Logiques, 1992. 